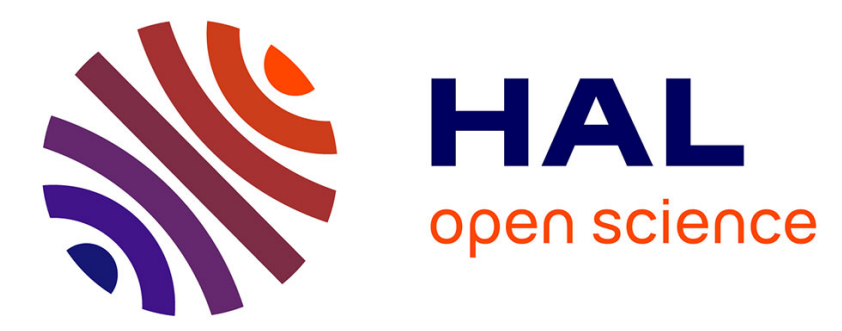

\title{
d.c. sputtering elaboration of thin films of the high-Tc superconductor YBa2Cu3O7-x: evidence for strong film-substrate interactions
}

\author{
A. Perrin, Z.Z. Li, O. Peña, J. Padiou, M. Sergent
}

\section{To cite this version:}

A. Perrin, Z.Z. Li, O. Peña, J. Padiou, M. Sergent. d.c. sputtering elaboration of thin films of the high-Tc superconductor YBa2Cu3O7-x: evidence for strong film-substrate interactions. Revue de Physique Appliquée, 1988, 23 (3), pp.257-264. 10.1051/rphysap:01988002303025700 . jpa-00245769

HAL Id: jpa-00245769

https://hal.science/jpa-00245769

Submitted on 1 Jan 1988

HAL is a multi-disciplinary open access archive for the deposit and dissemination of scientific research documents, whether they are published or not. The documents may come from teaching and research institutions in France or abroad, or from public or private research centers.
L'archive ouverte pluridisciplinaire HAL, est destinée au dépôt et à la diffusion de documents scientifiques de niveau recherche, publiés ou non, émanant des établissements d'enseignement et de recherche français ou étrangers, des laboratoires publics ou privés. 


\title{
d.c. sputtering elaboration of thin films of the high- $T_{c}$ superconductor $\mathrm{YBa}_{2} \mathrm{Cu}_{3} \mathrm{O}_{7-x}$ : evidence for strong film-substrate interactions
}

\author{
A. Perrin, Z. Z. Li, O. Peña, J. Padiou and M. Sergent \\ Laboratoire de Chimie Minérale B, U.A. C.N.R.S. n²54, Université de Rennes I, Avenue du Général \\ Leclerc, 35042 Rennes Cedex, France
}

(Reçu le 8 décembre 1987, accepté le 11 décembre 1987)

\begin{abstract}
Résumé. - Des couches minces supraconductrices du matériau $\mathrm{YBa}_{2} \mathrm{Cu}_{3} \mathrm{O}_{7-x}$ ont été préparées à partir de dépôts réalisés par pulvérisation diode continue puis cristallisés grâce à un traitement thermique approprié. Les paramètres de dépôt ont été optimisés afin d'y atteindre la stoechiométrie idéale $1: 2: 3$. Des substrats de nature variée ont été testés : la plupart d'entre eux mettent en évidence une forte interaction chimique avec le film lors du recuit. Afin de mieux définir les effets de contamination des divers substrats potentiels sur les propriétés supraconductrices de $\mathrm{YBa}_{2} \mathrm{Cu}_{3} \mathrm{O}_{7-x}$, des éléments étrangers ont été volontairement introduits en petites quantités dans des pastilles frittées de ce matériau. Leur influence a été étudiée par des mesures magnétiques. A partir de ces résultats, des couches minces supraconductrices ont été obtenues, notamment sur des substrats de zircone, de zircone stabilisée et de $\mathrm{BaZrO}_{3}$. Le début de transition se situe dans tous les cas vers $90 \mathrm{~K}$. L'importance de l'état de cristallisation des couches, lié au traitement thermique mis en œuvre, apparaît clairement.
\end{abstract}

\begin{abstract}
Superconducting thin films of $\mathrm{YBa}_{2} \mathrm{Cu}_{3} \mathrm{O}_{7-x}$ have been prepared by d.c. sputtering deposition followed by a suitable thermal treatment. The deposition parameters were optimized in order to obtain ideal $1: 2: 3$ composition of the films. A wide variety of substrates were tested, most of them giving evidence for a strong chemical interaction with the film when annealed. To better determine the contamination effects of potential substrates on the properties of $\mathrm{YBa}_{2} \mathrm{Cu}_{3} \mathrm{O}_{7-x}$, a number of foreign elements were diluted in sintered samples of the superconducting matrix. Their influence was evaluated from a.c. susceptibility or magnetization (SQUID) measurements. Superconducting films were thus obtained, mainly on zirconia, $\mathrm{BaZrO}_{3}$ or $\mathrm{YSZ}$ (yttrium stabilized zirconia) sintered plates, with the onset of superconducting transition occurring near $90 \mathrm{~K}$. The width of the transition strongly depends on the crystalline state of the film, which is connected to the applied thermal treatment.
\end{abstract}

\section{Introduction.}

The recent discovery of high- $T_{\mathrm{c}}$ superconductivity in metallic oxides with modified perovskite structure [1-2] started an intense activity in scientific and technological research. The preparation of thin films of these materials is of main interest for fundamental physical studies as well as for devices applications. So, a considerable effort is being done world-wide in this field, including a number of deposition techniques, for instance sputtering [3-7], electron beam coevaporation [8-9], MBE (molecular beam epitaxy) derived methods [10] and pulsed laser evaporation [11]. In a preliminary report [3], we have presented some results obtained on $\mathrm{Y}-\mathrm{Ba}-\mathrm{Cu}-\mathrm{O}$ deposited on a $\mathrm{ZrO}_{2}$ substrate. We report here our results obtained on the $\mathrm{Y}-\mathrm{Ba}-\mathrm{Cu}-\mathrm{O}$ system by d.c. sputtering on a variety of substrates. Since very strong chemical interactions between films and substrates should be taken into account, we completed this work by studying the contamination of superconducting material by some of the elements present in the composition of these substrates.

\section{Experimental.}

A very simple, small-sized d.c. sputtering device, as described elsewhere [12], was used. Only slight modifications were made in view of a more efficient cooling of the target and an easier control of the target-substrate distance [13].

Targets were made from appropriate amounts of $\mathrm{BaCO}_{3}, \mathrm{Y}_{2} \mathrm{O}_{3}$ and $\mathrm{CuO}$ mixed together, ground in 
aceton, reacted for 2 hours at $970{ }^{\circ} \mathrm{C}$ in an alumina boat under air atmosphere and air-quenched. The obtained powder was reground and pressed at an uniaxial pressure of $2 \mathrm{kbar}$ into the form of a disk of $25 \mathrm{~mm}$ diameter and $4 \mathrm{~mm}$ thickness. The disks were sintered again for 2 hours at $970{ }^{\circ} \mathrm{C}$ on a platinum plate and cooled down by switching off the furnace. Oppositely to $\mathrm{Sr}_{y} \mathrm{La}_{2-y} \mathrm{CuO}_{3-x}$, we never observed breaking of the targets during cooling [14]. The back of the targets (always contaminated by some crystals of platinum insulating compounds of the type $\mathrm{Ba}_{2} \mathrm{Y}_{2} \mathrm{CuPtO}_{8}$ recently characterized [15]) was glued using a silver epoxy to interchangeable copper holders.

Before pulverization, substrates were treated in a conventional manner: for instance, sapphire was degreased, cleaned in fluorhydric acid, washed with distilled water and ethanol in an ultrasonic cleaner and fired up to $1000-1200^{\circ} \mathrm{C}$ under air atmosphere. Sintered substrates were used as soon as possible after being removed from the furnace.

The films have been characterized by X-rays diffraction XRD $(\mathrm{CuK} \bar{\alpha})$ and by a scanning electron microscope (SEM) JEOL $35 \mathrm{CF}$ coupled to a NORTHERN TRACOR 2000 energy-dispersivespectroscopy (EDS) analyser. Resistivity measurements were performed using silver paint contacts in a standard four-probe method. The d.c. current was kept below $1 \mu \mathrm{A}-10 \mathrm{nA}$. The contact resistances $\left(0.5 \mathrm{~mm}^{2}\right.$ area) were of the order of $10 \Omega$. Magnetic measurements of the film plus the substrate were performed using a SHE-VTS SQUID magnetometer. Additional measurements on sintered pellets were also performed using the SQUID susceptometer or by a standard mutual inductance bridge operating at $119 \mathrm{~Hz}$.

\section{Results.}

Deposition was performed under pure argon atmosphere. The background pressure before sputtering was lower than $10^{-5}$ Torr. A presputtering time of 2 hours was used before each experiment in order to ascertainly reach the target equilibrium and to clean its surface, as some evolution was noticed when airexposed. Experiments performed with a high negative-polarization voltage (e.g. more than $500 \mathrm{~V})$ led to both a severe drop in current (meaning the formation of an insulating layer on the target's surface) and to a drastic change in composition of the deposited layer (which turned to be, in the worst cases, almost pure $\mathrm{Y}_{2} \mathrm{O}_{3}$ ). These films were of poor quality with SEM evidence for some back-sputtering. So, at least in the d.c. diode sputtering method, the polarization voltage has to be kept at a relatively low level.

Whatever the sputtering conditions used, the deposited layers had compositions quite different from the target : in all cases, they were enriched in $Y$ and $\mathrm{Cu}$. Therefore, the target composition was corrected in such a way to obtain a metal stoichiometry of the deposited layer as close as possible to the ideal $1: 2: 3$, within the accuracy of the EDS analytical method.
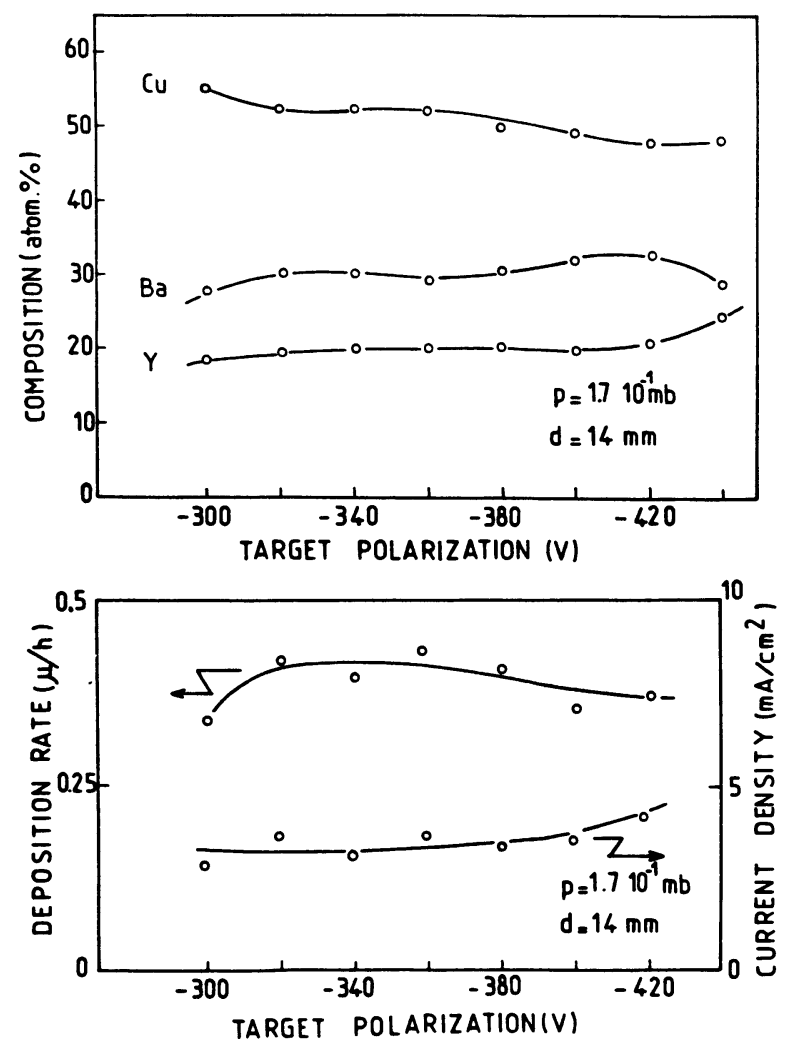

a)
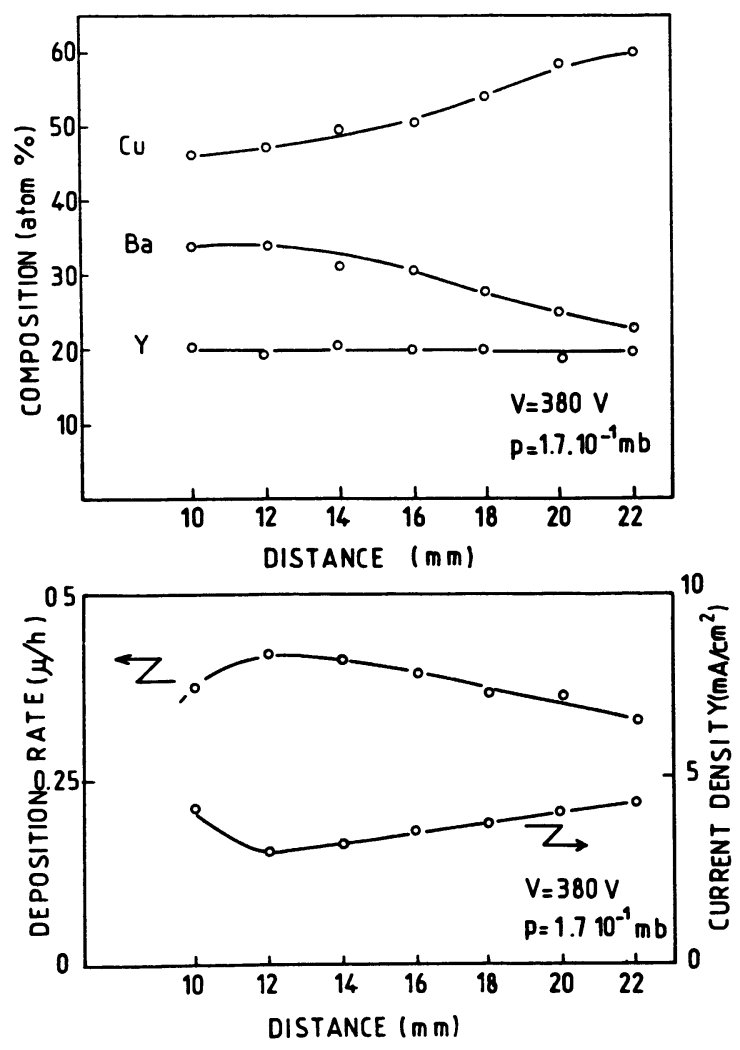

b)

Fig. 1. 

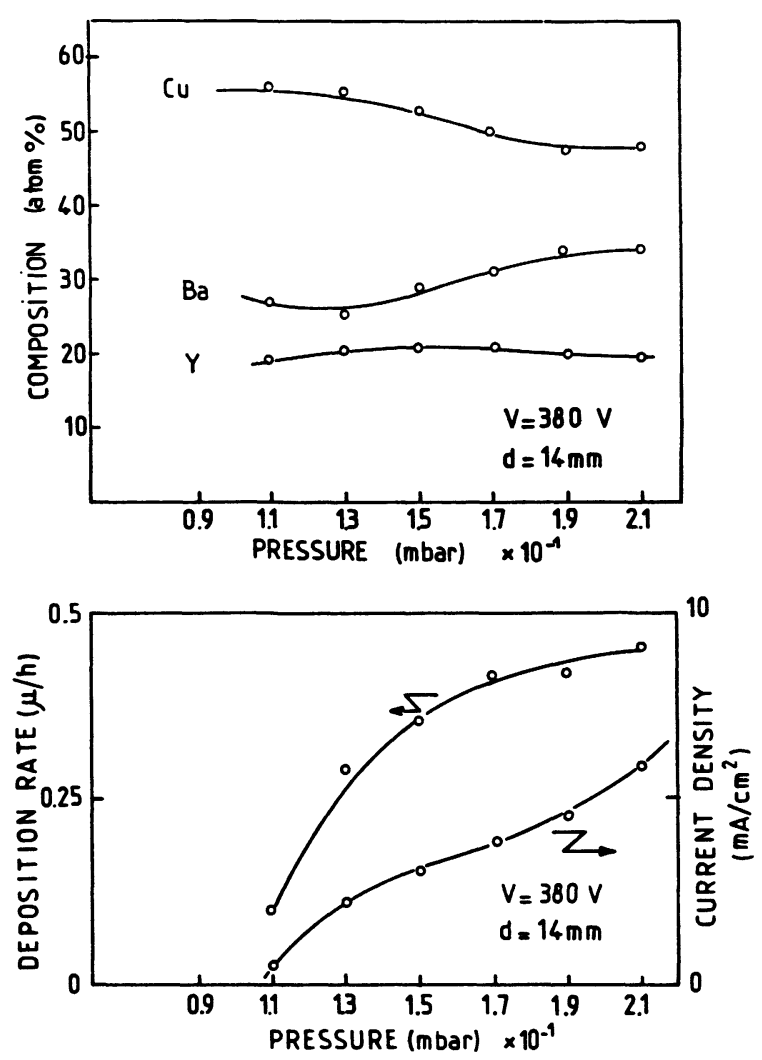

c)

Fig. 1. - Dependence of the film composition, current density and deposition rate on the sputtering conditions : a) polarization voltage ; b) target-substrate distance ; c) argon pressure.

The dependence of the film composition and deposition rate on the sputtering parameters, using the corrected target, is summarized in figure 1. Table I gives the sputtering conditions used in this work. The deposition rate was increased by a factor 3 or 4 by magnetron-assisted sputtering but the counterpart was a loss of homogeneity of the film.

The as-deposited films were shiny black (dark brown on transmission) with a specially smooth surface as shown in the SEM photograph displayed in figure 2. The roughness amplitude was estimated to be less than 20 to $30 \AA$ from mechanical stylus profilometer measurements. In addition these films were well-adherent and very difficult to scratch.

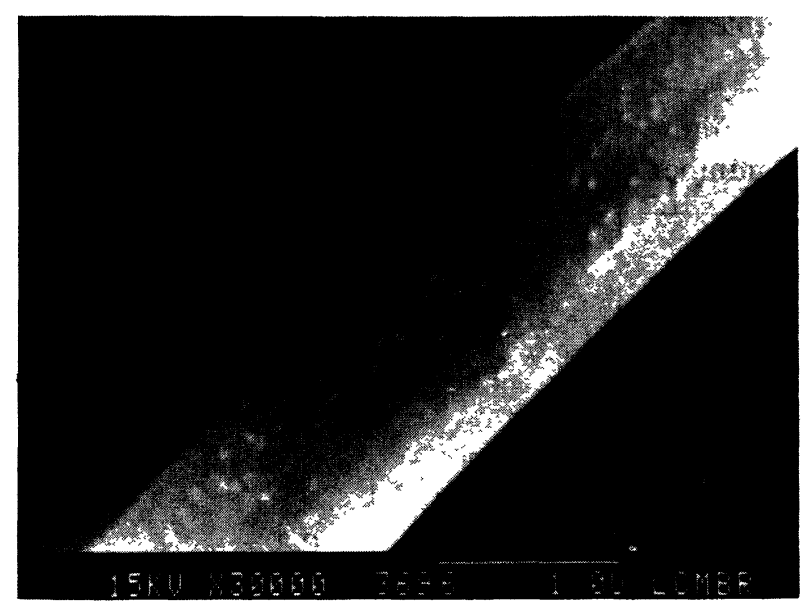

Fig. 2. - SEM micrograph of as-deposited film on a glass substrate (step obtained by chemical etching [23]). Film surface appears on the left, substrate surface on the right.

They were of amorphous type, similarly to other multinary compounds (Chevrel phases for instance [16]). Therefore, a thermal treatment of the films was necessary in order to reproduce as better as possible the crystallographic and superconducting properties of the bulk. In a parallel work, we have presented a systematic study of annealing conditions which optimize the superconducting parameters in sintered pellets $[17,18]$ but the greatest difficulty pointed out in the present work arises in fact from the film substrate interaction.

A number of substrates were tested and the results are summarized in table II. Sapphire is a classical substrate utilized in thin films technology and it could be reasonnably used for devices elaboration. The film-substrate interaction was specially studied in this case using XRD (Fig. 3). Some interactions start to occur at $440{ }^{\circ} \mathrm{C}$ leading to the formation of aluminates like $\mathrm{Ba}_{4} \mathrm{Al}_{2} \mathrm{O}_{7}$ (and may be $\mathrm{Y}_{4} \mathrm{Al}_{2} \mathrm{O}_{9}$ ) as suggested by the broad peak near $2 \theta=30^{\circ}(\mathrm{CuK} \bar{\alpha}$ radiation) which does not appear on other substrates. In addition, an appreciable amount of $\mathrm{BaCO}_{3}$ clearly appears : it would be due to a reaction of baryum in a very reactive form in the film - with atmospheric carbon dioxide. On the other hand, at temperatures higher than $800{ }^{\circ} \mathrm{C}$, crystallization of the $1: 2: 3$ phase occurs (Figs. $3 a$ and 4 ) but some

Table I. - Selected sputtering conditions used in this work.

Target polarization $V:-380 \mathrm{~V}$

Argon pressure : $1.3 .10^{-1}$ Torr

Presputtering time : 2 hours

Deposition rate : $67 \AA . \mathrm{mn}^{-1}$

Target composition : $\mathrm{Y}_{0.82} \mathrm{Ba}_{3} \mathrm{Cu}_{3} \mathrm{O}_{x}$
Current density $J: 8 \mathrm{~mA} \mathrm{~cm} \mathrm{~cm}^{-2}$

Target substrate distance : $14 \mathrm{~mm}$

Sputtering time : 2-4 hours

Film thickness : $1-2 \mu \mathrm{m}$

Film composition : $\mathrm{YBa}_{2} \mathrm{Cu}_{3} \mathrm{O}_{x}(*)$

(*) as determined from EDS data calibrated against bulk single crystals. 
Table II. - Examples of the influence of substrates on thin films composition.

\begin{tabular}{|c|c|c|c|c|}
\hline $\begin{array}{l}\text { Film } \\
\text { number }\end{array}$ & Substrate & $\begin{array}{l}\text { Annealing } \\
\text { conditions }\end{array}$ & Secondary phases & $\begin{array}{l}\text { Average film composition } \\
\quad \text { (atom percent) }\end{array}$ \\
\hline C.19.1 & boron nitride & $900 / 1 \mathrm{~h}$ & borates & no $1: 2: 3$ phase \\
\hline D.10.2 & $\mathrm{Ag}$ & $920 / 30 \mathrm{~min}$ & $\mathrm{Y}_{2} \mathrm{BaCuO}_{5}, \mathrm{Y}_{2} \mathrm{O}_{3}$ & $16: 36: 48$ \\
\hline D.1.1 & $\mathrm{Au}$ & $900 / 1 \mathrm{~h}+$ s.c. & $\mathrm{Y}_{2} \mathrm{BaCuO}_{5}(*)$ & $22: 37: 42$ \\
\hline D.6.3 & $\mathrm{Pt}$ & $820 / 1 \mathrm{~h}$ & $\begin{array}{l}\mathrm{CuO}, \mathrm{Y}_{2} \mathrm{BaCuO}_{5} \\
+\mathrm{Ba}_{2} \mathrm{Y}_{2} \mathrm{CuPtO}_{8} ?\end{array}$ & $15: 33: 51$ \\
\hline B.8.1 & $\mathrm{Si}$ & $820 / 30 \mathrm{~min}$ & $\begin{array}{l}\mathrm{CuO}, \mathrm{Y}_{2} \mathrm{Cu}_{2} \mathrm{O}_{5}, \mathrm{Ba}_{2} \mathrm{SiO}_{4} \\
\mathrm{BaSiO}_{3}\end{array}$ & no $1: 2: 3$ phase \\
\hline B.7.1 & $\mathrm{SiO}_{2}$ & $950 / 2 \mathrm{~h}$ & idem & no $1: 2: 3$ phase \\
\hline C.1.3 & sapphire & $820 / 3 \mathrm{~h}$ & $\mathrm{BaAl}_{2} \mathrm{O}_{4}, \mathrm{CuO}$ & \\
\hline D.4.1 & sapphire & $920 / 1 \mathrm{~h}$ & $\mathrm{BaAl}_{2} \mathrm{O}_{4}, \mathrm{Y}_{2} \mathrm{BaCuO}_{5}, \mathrm{CuO}$ & $15: 19: 66$ \\
\hline D.4.3 & sapphire & $900 / 1 \mathrm{~h}$ & $\begin{array}{l}\mathrm{BaAl}_{2} \mathrm{O}_{4}, \mathrm{Y}_{2} \mathrm{BaCuO}_{5}, \mathrm{CuO} \\
\text { (lower concentration) }\end{array}$ & $14: 22: 63$ \\
\hline D.14.5 & sapphire & $900 / 1 \mathrm{~h}+$ s.c. & $\mathrm{BaCuO}_{2}, \mathrm{BaAl}_{2} \mathrm{O}_{4}$ (weak) & $16: 28: 55$ \\
\hline C.14.1.A & $\mathrm{ZrO}_{2}$ & 950/5 $\min +$ s.c. & $\mathrm{BaZrO}_{3}, \mathrm{CuO}$ & \\
\hline C.30.3 & YSZ & $900 / 1 \mathrm{~h}$ & $\mathrm{BaZrO}_{3}, \mathrm{CuO}$ & \\
\hline D.9.2 & YSZ & $850 / 1$ h + s.c. & $\mathrm{BaZrO}_{3}, \mathrm{CuO}$ & $12: 24: 64$ \\
\hline D.11.1 & $\mathrm{SrTiO}_{3}$ & $900 / 1 \mathrm{~h}+$ s.c. & $\mathrm{CuO}$ (very weak) & $19: 34: 47$ (diffusion $\mathrm{Sr}$ ) \\
\hline C. 25.2 & $\mathrm{BaZrO}_{3}$ & $875 / 10 \mathrm{~min}+$ s.c. & $\mathrm{CuO}$ & $17: 33: 50$ \\
\hline D.12.7 & $\mathrm{BaTiO}_{3}$ & $825 / 1$ h + s.c. & $\mathrm{CuO}$ (very weak) & $15: 31: 54$ \\
\hline D.13.6 & $\mathrm{Y}_{2} \mathrm{BaCuO}_{5}$ & $900 / 1 \mathrm{~h}+$ s.c. & $\mathrm{Y}_{2} \mathrm{O}_{3}, \mathrm{CuO}$ (very weak) & $16: 34: 50$ \\
\hline
\end{tabular}

Series B and C: annealed under air; series D : annealed under oxygen ; s.c. : slow cooling. $\left(^{*}\right)$ unknown peak $d=3.23$.

$\mathrm{BaAl}_{2} \mathrm{O}_{4}$ is formed. Above $970{ }^{\circ} \mathrm{C}$, strong preferential orientation appears as $00 l$ peaks are considerably enhanced : however these films are highly resistive. Very short heat treatments (some minutes) between 850 and $950^{\circ} \mathrm{C}$ lead to the perovskite-type phase but these films present a superconducting transition only at low temperature (for instance, a $T_{\mathrm{c}}$ onset of $10 \mathrm{~K}$ was observed for a film annealed $3 \mathrm{~min}$ at $950{ }^{\circ} \mathrm{C}+$ $3 \mathrm{~min}$ at $650^{\circ} \mathrm{C}+30 \mathrm{~min}$ at $440^{\circ} \mathrm{C}$ ). In addition, careful inspection of $\mathrm{X}$-rays patterns points out some anomalies : for instance, the peaks 020,006 and 200 (near $2 \theta=47^{\circ}$ ) overlap, suggesting the presence of a tetragonal phase. The same feature appears in the $\mathrm{X}$-rays powder pattern of $\mathrm{YBa}_{2} \mathrm{Cu}_{3} \mathrm{O}_{7-x}: 0.1 \mathrm{Al}$ (Fig. 3b) which indicates that a small amount of aluminium may stabilize a tetragonal-like phase. On the other hand, when thin-films are annealed under pure oxygen, the usual splitting ot the 020, 006 and 200 peaks is preserved, although intensities inversions are observed. This difference, which is reflected in the resistivity behaviour improvement (Fig. 5) (also recently noticed by $\mathrm{H}$. Adachi et al. [7]) is unexpected because bulk samples behave very similarly when annealed either under air or oxygen [18]. A possible explanation may be the air formation of baryum carbonate which inhibits a quick crystallization of the material, and thus favours the competi- tive film-substrate interaction. The diffusion of $\mathrm{Ba}$ and, in a smaller extent of $\mathrm{Y}$, in the sapphire substrate is directly proved by the presence of small quantities of baryum and yttrium aluminates leading therefore to the presence of a small amount of $\mathrm{CuO}$. It is also indirectly shown by a systematic shift of the film average composition after annealing, as $\mathrm{Ba}$ and $\mathrm{Y}$ contents tend to decrease and $\mathrm{Cu}$ content tends to increase by some percent.

The choice of other substrates was subjected to preliminary tests on the poisoning effects of foreign elements in the superconducting $\mathrm{YBa}_{2} \mathrm{Cu}_{3} \mathrm{O}_{7-x}$ compound. For instance, such elements as $\mathrm{Al}, \mathrm{Ti}, \mathrm{Mg}$ or $\mathrm{Zr}$, (found in potential substrates like $\mathrm{Al}_{2} \mathrm{O}_{3}$, $\mathrm{BaTiO}_{3}, \mathrm{MgO}$ or $\mathrm{ZrO}_{2}$ ) were respectively diluted in proportions of 0.1 atom/formula into a $1: 2: 3$ matrix. Pellets were sintered and annealed by a standard routine $[17,18]$ and the diamagnetic response was recorded. Strong degradation of superconductive transition by aluminium, magnesium or titanium clearly appears in figure 6 . In contrast, zirconium presents little or not influence on $T_{\mathrm{c}}$ and/or the transition width. In the case of $\mathrm{Al}$ dopant, SEM and microprobe analyses show the presence of thick melted grain-boundaries containing a large concentration of aluminium, in agreement with the presence of secondary phases observed in XRD 


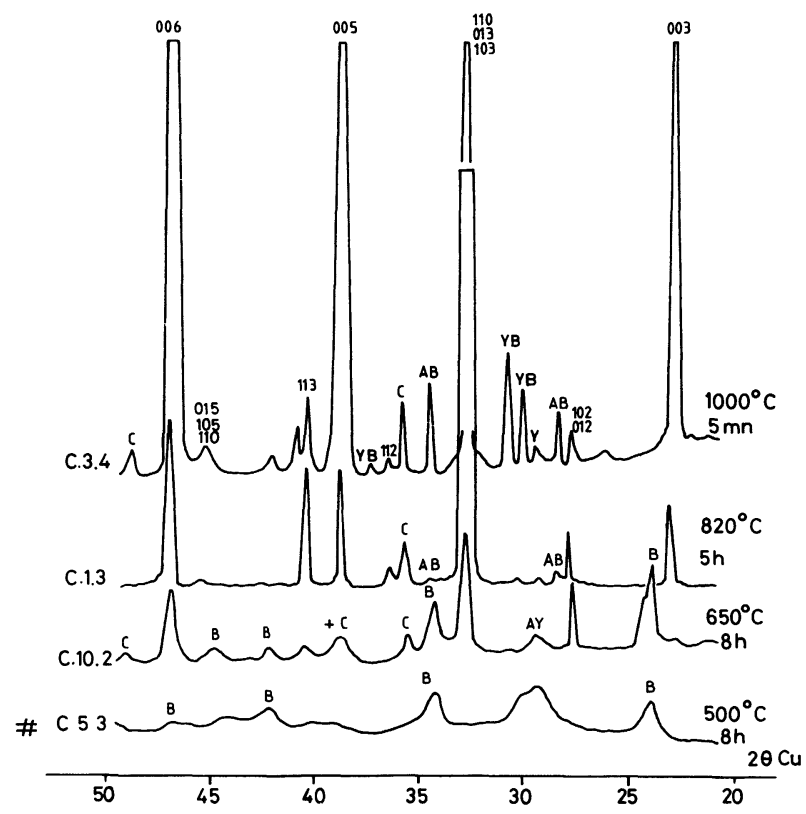

a)

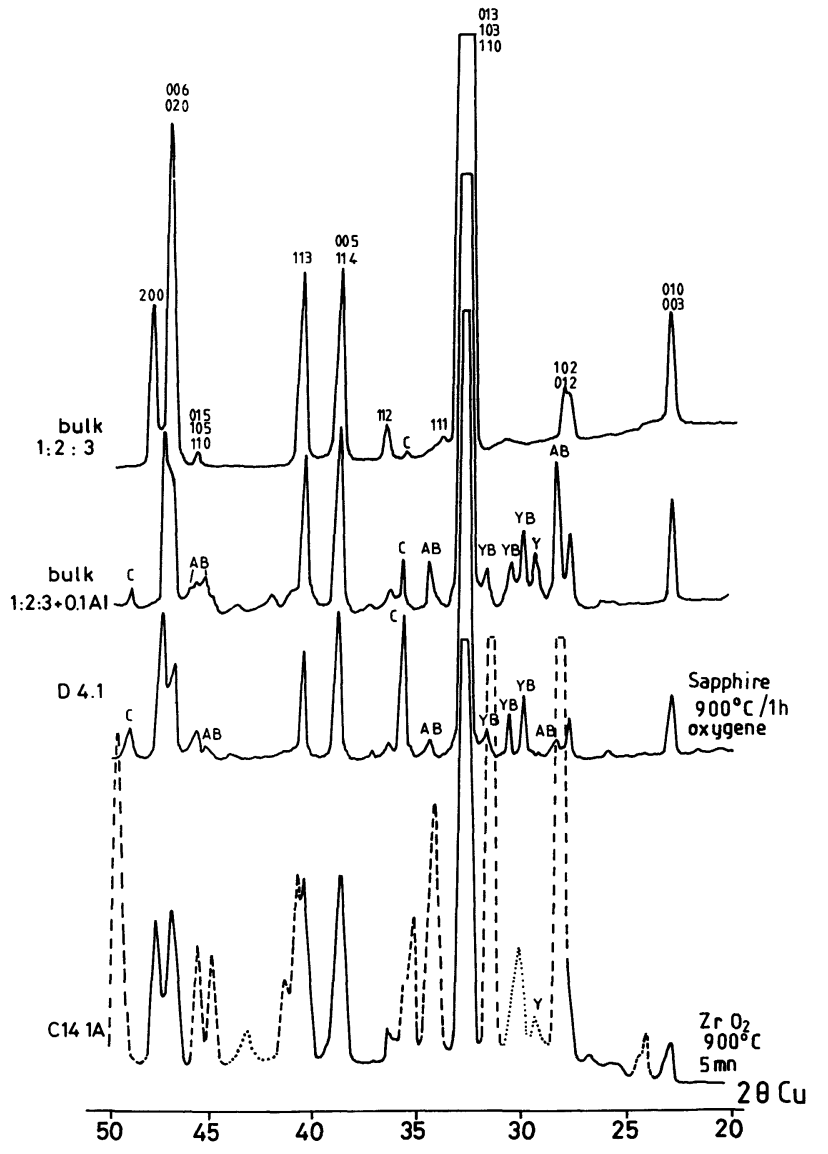

b)

Fig. 3. - a) typical X-rays diffraction patterns of thin films deposited on sapphire substrates and annealed at various temperatures under air atmosphere. Secondary phases are denoted by the symbols: $\mathrm{Y}=\mathrm{Y}_{2} \mathrm{O}_{3} ; \mathrm{B}=\mathrm{BaCO}_{3}$; $\mathrm{C}=\mathrm{CuO} ; \quad \mathrm{AY}=\mathrm{YAlO}_{3} ; \quad \mathrm{AB}=\mathrm{BaAl}_{2} \mathrm{O}_{4} ; \quad \mathrm{YB}=$ $\mathrm{Y}_{2} \mathrm{BaCuO}_{5}$.

REVUE DE PHYSIQUE APPLIQUEE. - T. 23, N 3, MARS 1988

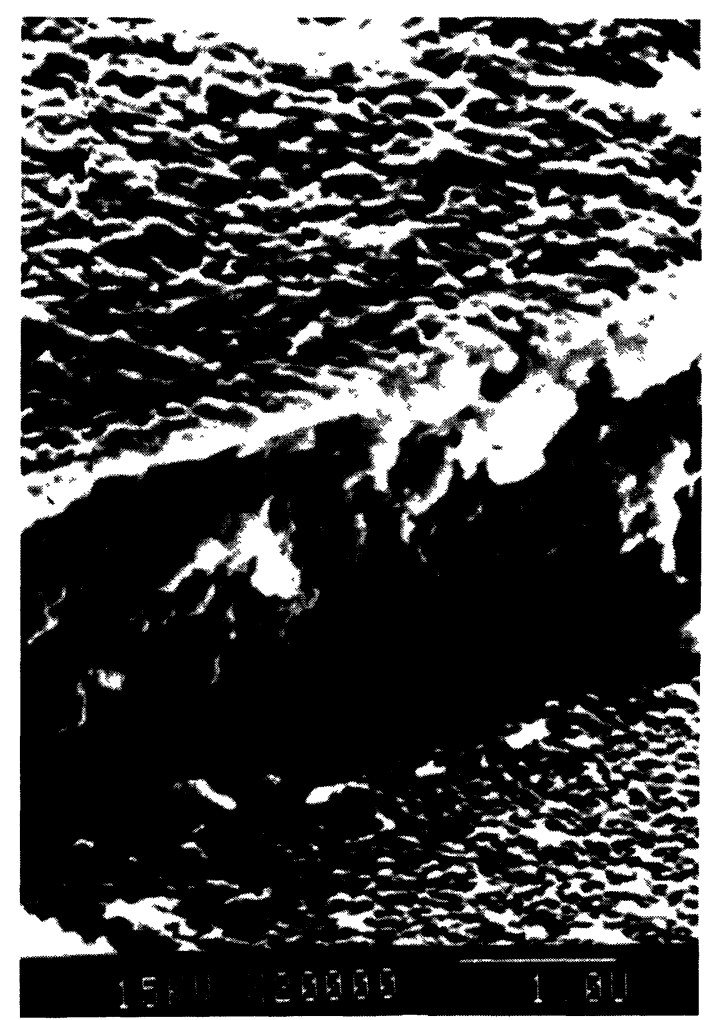

Fig. 4. - SEM micrograph of a film deposited on a sapphire substrate and annealed one hour at $880^{\circ} \mathrm{C}$. Step obtained by scratching. Note the rough aspect of the substrate surface (downpart) due to chemical interaction.

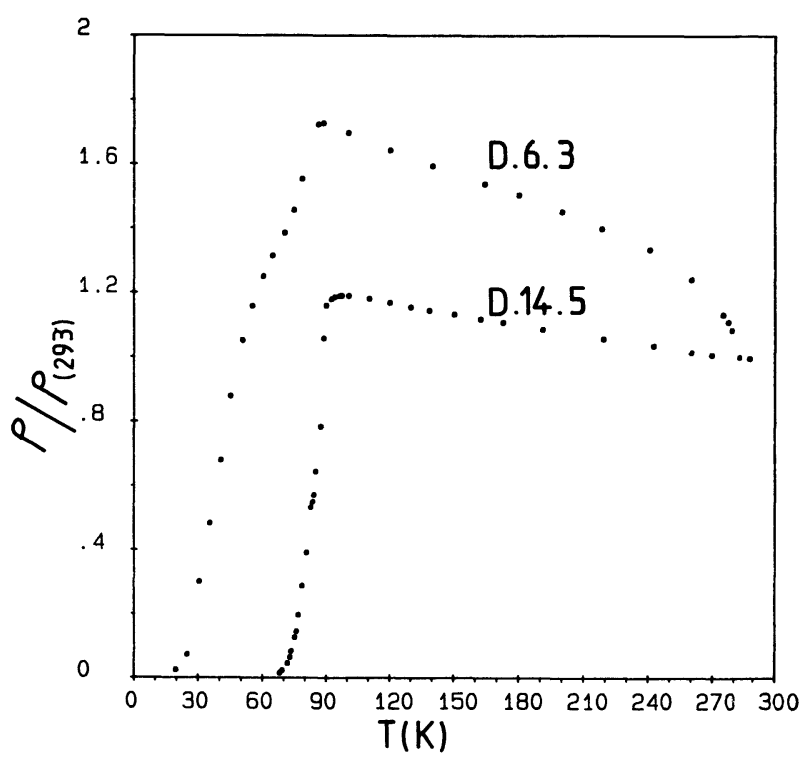

Fig. 5. - Resistivity versus temperature for films deposited on platinum (D.6.3) and sapphire (D.14.5) substrates and annealed under oxygen.

b) comparison of XRD patterns of $\mathrm{YBa}_{2} \mathrm{Cu}_{3} \mathrm{O}_{7-x}$ (bulk), $\mathrm{YBa}_{2} \mathrm{Cu}_{3} \mathrm{O}_{7-x}$ doped with $0.1 \mathrm{Al}$ (bulk), a film deposited on sapphire and annealed under oxygen flow (compare Fig. 3a), and a film deposited on zirconia substrate (--- substrate ; .... $\mathrm{BaZrO}_{3}$ ).

Note the vertical enlargement in order to make the secondary phases peaks more visible. 


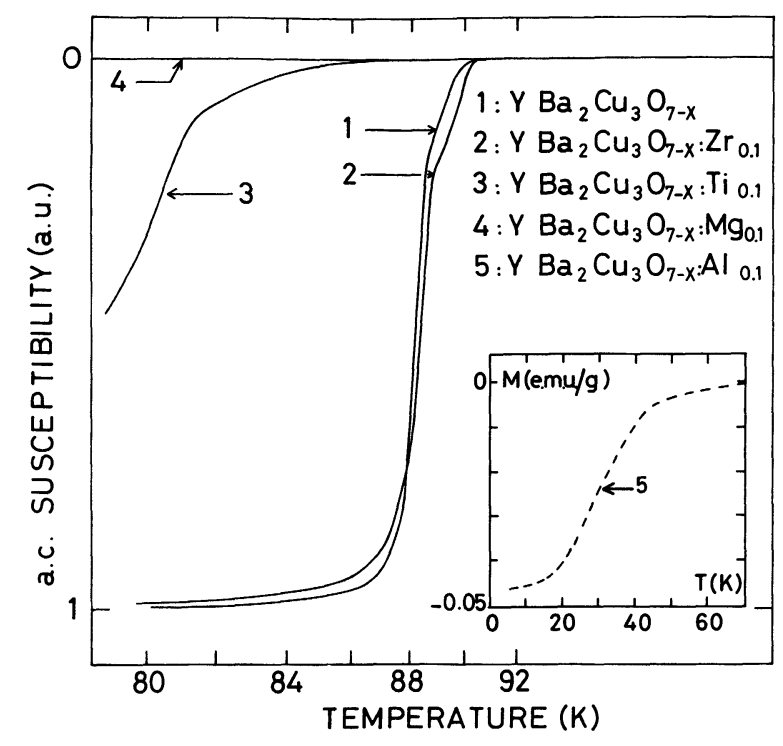

Fig. 6. - Diamagnetic responses of sintered pellets of pure $\mathrm{YBa}_{2} \mathrm{Cu}_{3} \mathrm{O}_{7-x}$ samples doped with $\mathrm{Zr}, \mathrm{Ti}, \mathrm{Mg}$, and Al.

patterns. Also platelet crystals of the $1: 2: 3$ compound contain an appreciable concentration (some atom percent) of $\mathrm{Al}$. In contrast, in the case of $\mathrm{Zr}$ doping, grain boundaries are thin with no detectable zirconium in the crystals, the contaminant appearing only as small isolated $\mathrm{BaZrO}_{3}$ single-crystals. Thus, the choice was oriented toward zirconia, yttrium stabilized zirconia (YSZ) and $\mathrm{BaZrO}_{3}$ substrates, and sintered plates of these materials were then made.

Typical results concerning thin films on zirconium based substrates are given in figure $3 b, 7$ and 8 . $\mathrm{X}$-rays diffraction data, reported here in the case of $\mathrm{ZrO}_{2}$ substrate clearly shows the splitting of the peaks 200 and 020, 006, as expected in the or-

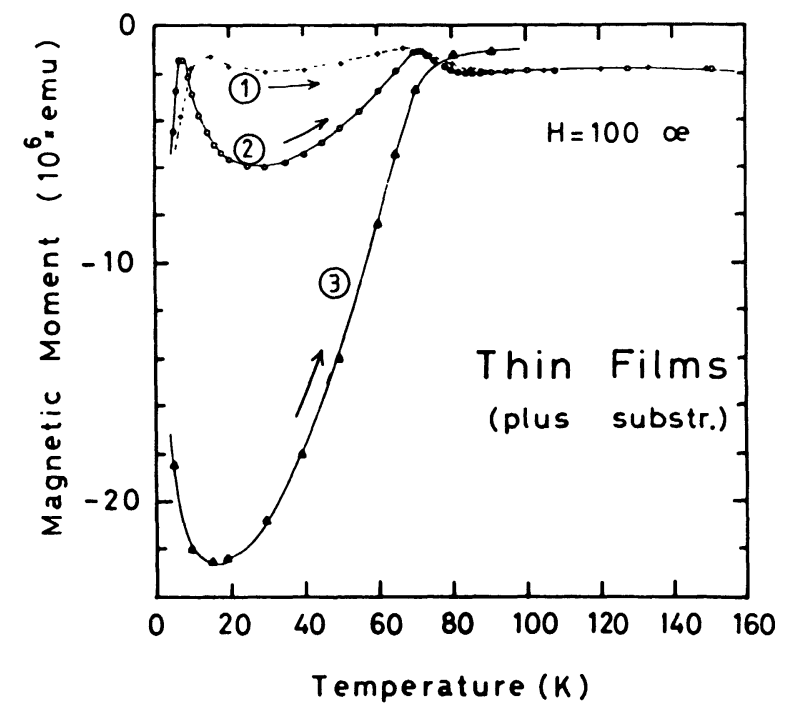

Fig. 7. - Magnetic susceptibility of films deposited on zirconium-based substrates and short time annealed at $900{ }^{\circ} \mathrm{C}$ under air atmosphere (see text). thorhombic perovskite phase. A small amount of $\mathrm{BaZrO}_{3}$ (which tends to increase with temperature and duration of annealing) appears in this case, showing slight interaction. Figure 7 shows the temperature dependence of the magnetic moment $M$ of Y-Ba-Cu-O thin films deposited on three different substrates. The magnetic moment is computed without correction of the substrate's moment. Also, the weight of the about one-micrometer-thick films being unknown, the moment is given in absolute units (emu) and not in gram units (emu/gram). Those films made on $\mathrm{BaZrO}_{3}$ substrates (curves 1 and 2) present similar features, although different in amplitude : a clear peak at around $70 \mathrm{~K}$, followed by a slight decrease of the magnetic moment with decreasing temperature. The increase at still lower temperatures may indicate the presence of paramagnetic impurities in the substrate, before a last collapse of $M$ below $15 \mathrm{~K}$, due to the diamagnetic state of the film. Film $\mathrm{n}^{\circ}$ C.14.1, which was deposited on a $\mathrm{ZrO}_{2}$ substrate shows the onset of a diamagnetic state situated around $80 \mathrm{~K}$ and a large decrease of the moment is seen down to $20 \mathrm{~K}$ (curve 3 ).

Even though a different magnetic response was obtained on the three films, probably due to the substrate influence, their resistivity behaviour was strictly the same, independently on the substrate. Curve 1 of figure 8 shows the temperature dependence of the resistance ratio $R(T) / R(293 \mathrm{~K})$ for one of these films. The semiconducting-like resistivity from room-temperature down to $90 \mathrm{~K}$ is probably due to grain boundaries or localization effects, as the film is still rather amorphous in character due to short annealing. In addition it has to be em-

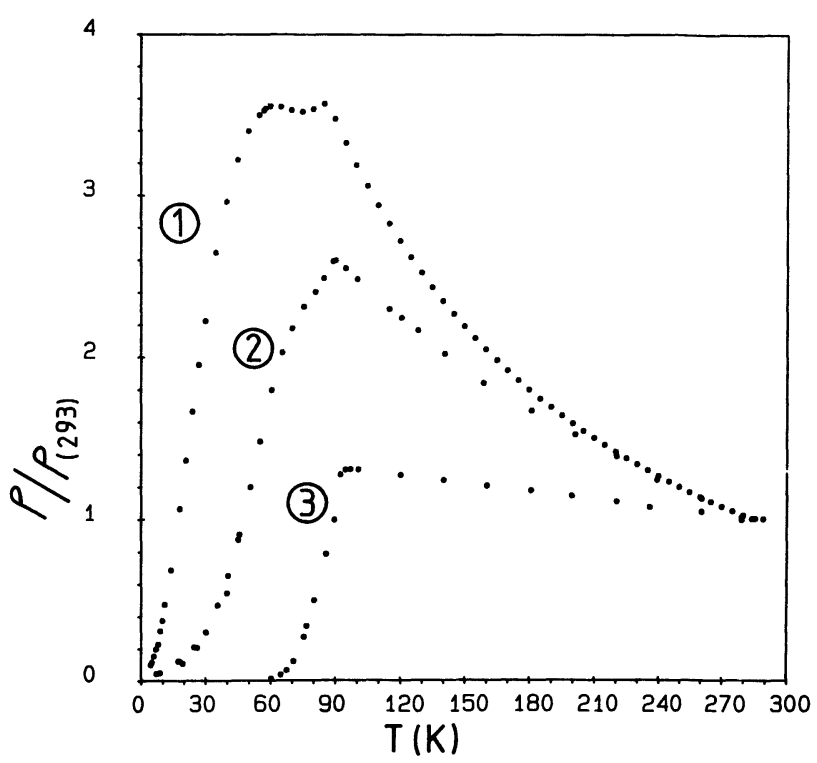

Fig. 8. - Resistivity versus temperature for films deposited on zirconia : 1) C.14.1, air annealed $900^{\circ} \mathrm{C} / 5 \mathrm{~min}+$ $440{ }^{\circ} \mathrm{C} / 20 \mathrm{~min}\left(\mathrm{ZrO}_{2}\right)$ [3]. 2) D.7.3, oxygen annealed $900^{\circ} \mathrm{C} / 5 \mathrm{~min}$ (direct heating) and slowly cooled down to $400^{\circ} \mathrm{C}$. 3) D.9.2, oxygen annealed $850^{\circ} \mathrm{C}$ (slow heating) and step cooled (YSZ sintered substrate). 
phasized that the thermal linear expansion coefficient of the material is large, close to 1.5$3 \times 10^{-5}{ }^{\circ} \mathrm{C}^{-1}$, leading to important film strain. However, clear anomalies appear at $90 \mathrm{~K}$ and $60 \mathrm{~K}$, which indicate the onset of a superconductor state. The double bump of the resistivity may be correlated in fact to the inflection points of the a.c. susceptibility and resistivity of bulk samples [19]. This means that the peak at $90 \mathrm{~K}$ would correspond to the onset of the superconducting state inside each grain, whereas at $60 \mathrm{~K}$ a coherence transition begins to take place [20]. Similar features have been already observed in thin films deposited on sapphire or $\mathrm{SrTiO}_{3}$ substrates [7]. Below $60 \mathrm{~K}$, a large decrease of the resistivity is observed down to $5 \mathrm{~K}$, where a zero-resistance state is obtained. When film crystallization is improved by a longer annealing this double bump disappears and the transition becomes narrower, while the resistive ratio before the transition is decreased as shown in curves 2 and 3 of figure 8 . Both the resistive and inductive measurements presented here clearly indicate that superconducting thin films of the high- $T_{\mathrm{c}}$ superconductor $\mathrm{YBa}_{2} \mathrm{Cu}_{3} \mathrm{O}_{7-x}$ can be prepared as good as sintered samples, provided that a proper substrate and a suitable annealing are used. Similar results on YSZ substrates are presented in a parallel work which came to our attention while writing this paper [21] : after a short annealing time at $895^{\circ} \mathrm{C}$ a resistivity behaviour very similar to that of curve 1 in figure 8 is observed. Subsequent annealings make the transition at $90 \mathrm{~K}$ to become sharper at least on (100) YSZ single crystal surfaces. The improvement of resistivity when passing from sintered to single-crystal substrates (although in this case there is no epitaxy) also reflects the importance of film-substrate interaction as the specific surface of the latter decreases in a large extent.

\section{Conclusion.}

In this work we succeeded in the deposition of thin layers of yttrium-baryum-copper oxide with a metallic stoichiometry very close to $1: 2: 3$ using a very simple d.c. sputtering device. It is emphasized that the main difficulty to reach good superconducting films arises from film-substrate interactions which, in turn, leads to some limitations in achieving the best possible thermal treatment. As it is shown that zirconium does not damage the bulk superconduc- tivity of the high- $T_{\mathrm{c}}$ compound, materials like zirconia, YSZ or $\mathrm{BaZrO}_{3}$ appear to be good candidates as thin film substrates or buffer layers. Work is in progress in order to improve the superconducting properties of $\mathrm{YBa}_{2} \mathrm{Cu}_{3} \mathrm{O}_{7-x}$ thin films deposited on such substrates and will be published soon. This improvement will be reached by optimizing both the thermal treatment and the initial composition in view to compensate the slight diffusion of the metallic components (mainly $\mathrm{Ba}$ in this case) into the substrate. An alternative route is to look for substrates giving very small interactions : as an illustration, figure 9 displays the resistivity behaviour of a film deposited on a sintered plate of the insulating $\mathrm{Y}_{2} \mathrm{BaCuO}_{5}$ material. A very sharp transition is achieved [22], even before any attempt of improving the substrate's surface quality.

\section{Acknowledgments.}

This work was supported by the Centre National d'Etudes des Télécommunications, Center of Lannion $\mathrm{B}$, under contract $\mathrm{n}^{\circ} 858 \mathrm{~B} 095$. We also would like to thank Mrs. F. Thoumyre (Physics Dep., Institut National des Sciences Appliquées, Rennes) for thickness measurements.

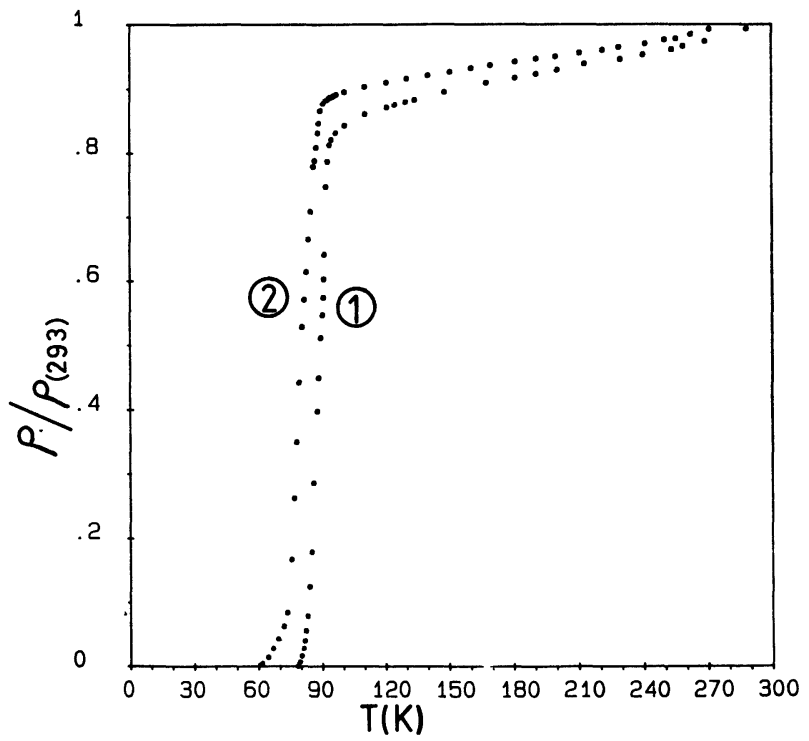

Fig. 9. - Superconducting transition of a $\mathrm{YBa}_{2} \mathrm{Cu}_{3} \mathrm{O}_{7-x}$ film deposited on a $\mathrm{Y}_{2} \mathrm{BaCuO}_{5}$ pressed plate (curve 1, sample $n^{\circ} \mathrm{D}$.13.6). For comparison is given the temperature dependence of the film $\mathrm{n}^{\circ}$ D.11.1 deposited on sintered $\mathrm{SrTiO}_{3}$ (curve 2). The thermal treatment was identical for both samples.

\section{References}

[1] Bednorz, J. G. and Muller, K. A., Z. Phys. B 64 (1986) 189.

[2] Wu, M. K., Ashburn, J. R., Torng, C. T., Hor, P. H., MENG, R. L., GaO, L., Huang, Z. J., Wang, Y. Q., Chu, C. W., Phys. Rev. Lett. 58 (1987) 908.
[3] Lebeau, C., Li, Z. Z., Padiou, J., Peña, O., Perrin, A., Perriñ, C., Peyral, P., Raboutou, A., Rosenblatt, J. and Sergent, M., Proc. Ist Europ. Workshop on High-Tc Superconductors and Potential Applications, Genova (1987) p. 357. 
[4] Hong, M., Liou, S. H., Kwo, J. and Davidson, B. A., Appl. Phys. Lett. 51 (1987) 694.

[5] Kawasaki, M., Nagata, S., Sato, Y., Funabashi, M., Hasegawa, T., Kishio, K., Kitazawa, K., Fueki, K. and Koinuma, H., Jpn J. Appl. Phys. 5 (1987) L738.

[6] Blamire, M. G., Somekh, R. E., Morris, G. W., Tomlinson, E. J. and EvetTs, J. E., Proc. Ist Europ. Workshop on High-Tc Superc., Genova (1987) p. 129.

[7] Adachi, H., Setsune, K., Mituyu, T., Hirochi, K., ICHIKAWA, Y., Kamada, T. and WASA, K., Jpn J. Appl. Phys. 5 (1987) L709.

[8] Oh, B., Naito, M., Arnagon, S., Rosenthal, P., Barton, R., Beasley, M. R., Geballe, T. H., HAMmOND, R. H. and KAPITULNIK, A., Appl. Phys. Lett. 51 (1987) 852.

[9] Tsaur, B. Y., Dilorio, M. S., Strauss, A. J., Appl. Phys. Lett. 51 (1987) 858.

[10] Kwo, J., Hsieh, T. C., Fleming, R. M., Hong, M., Liou, S. H., Davidson, B. A. and Keldman, L. C., Phys. Rev. B 36 (1987) 4039.

[11] Dijkkamp, D., Venkatesan, T., Wu, X. D., ShaheER, S. A., JisRawi, N., Min-LeE, Y. H., Mclean, W. L. and Croft, M., Appl. Phys. Lett. 51 (1987) 619.

[12] Quéré, Y., Perrin, A., Horyn, R. and Sergent, M., Mat. Lett. 3 (1985) 340.
[13] QUÉRÉ, Y., Thesis, Rennes (1986).

[14] LI, Z. Z. and PERrIN, A., unpublished.

[15] Laligant, Y., Ferey, G., Hervieu, M. and Raveau, B., Europhys. Lett. 4 (1987) 1023.

[16] Quéré, Y., Perrin, A., Padiou, J., Perrin, C., SEIGNAC, A., Horyn, R. and Sergent, M., Ann. Chim. 7-8 (1984) 1065.

[17] Perrin, A., Peña, O., Perrin, C., Sergent, M. and Le Traon, J. Y., French Patent $\mathrm{n}^{\circ} 87$ 07315, 25 mai 1987.

[18] Perrin, A., Peña, O., Perrin, C., Li, Z. Z. and Sergent, M., J. Phys. (in the press).

[19] Beyers, R., Lim, G., ENGler, E. M., Lee, V. Y., RAMIREZ, M. L., SAVOY, R. J., JACOWITZ, R. D., Shaw, T. M., La Placa, S., Boehme, R., TsueI, C. C., Park, S. I., Shafer, M. W. and Gallager, W. J., Appl. Phys. Lett. 51 (1987) 614.

[20] Raboutou, A., Peyral, P., Rosenblatt, J., lebeau, C., Peña, O., Perrin, A., Perrin, C., Sergent, M., Europhys. Lett. 4 (1987) 1321.

[21] Bruyère, J. C., Marcus, J., Reydet, P. L., EsCRIBE-FILIPPINI, C., SCHLENKER, C., private communication (to appear in Mater. Res. Bull.).

[22] Perrin, A., Li, Z. Z., Padiou, J., Peña, O., SERGENT, M., to be published.

[23] Thoumyre, F., Li, Z. Z., Perrin, A., Dousselin, G., unpublished results. 